Meta

Journal des traducteurs

Translators' Journal

\title{
Investigating Domain Conceptualisation and Scene Construal in Trainee Translators
}

\section{Maeve Olohan}

Volume 45, numéro 4, décembre 2000

URI : https://id.erudit.org/iderudit/003763ar

DOI : https://doi.org/10.7202/003763ar

Aller au sommaire du numéro

Éditeur(s)

Les Presses de l'Université de Montréal

ISSN

0026-0452 (imprimé)

1492-1421 (numérique)

Découvrir la revue

Citer cet article

Olohan, M. (2000). Investigating Domain Conceptualisation and Scene

Construal in Trainee Translators. Meta, 45(4), 593-608.

https://doi.org/10.7202/003763ar

\section{Résumé de l'article}

Empruntées à la linguistique cognitive, les notions de conceptualisation de domaine et de décomposition scénique sont brièvement présentées puis étudiées dans le contexte de la traduction pour expliquer le traitement qui s'opère lors de la traduction. Ce qui est notamment intéressant, c'est le lien qui existe entre la conceptualisation de domaine chez les étudiants et l'accroissement de leur compétence linguistique et traductionnelle. Les données tirées d'études à voix haute effectuées avec des étudiants de niveaux inter- médiaire et avancé nous fournissent une certaine preuve de l'étendue d'une conscience conceptuelle lorsqu'ils traduisent de l'allemand à l'anglais. En conclusion, l'auteur affirme que les modèles de traitement cognitif sous-jacents à la linguistique cognitive peuvent aussi servir à expliquer comment et pourquoi se produisent les procédés de la traduction examinés en traductologie sur corpus, à savoir l'explicitation et la normalisation. 


\title{
Investigating Domain Conceptualisation and Scene Construal in Trainee Translators
}

\author{
MAEVE OLOHAN \\ University of Science and Technology in Manchester, Manchester, United Kingdom
}

\begin{abstract}
RÉSUMÉ
Empruntées à la linguistique cognitive, les notions de conceptualisation de domaine et de décomposition scénique sont brièvement présentées puis étudiées dans le contexte de la traduction pour expliquer le traitement qui s'opère lors de la traduction. Ce qui est notamment intéressant, c'est le lien qui existe entre la conceptualisation de domaine chez les étudiants et l'accroissement de leur compétence linguistique et traductionnelle. Les données tirées d'études à voix haute effectuées avec des étudiants de niveaux intermédiaire et avancé nous fournissent une certaine preuve de l'étendue d'une conscience conceptuelle lorsqu'ils traduisent de l'allemand à l'anglais. En conclusion, l'auteur affirme que les modèles de traitement cognitif sous-jacents à la linguistique cognitive peuvent aussi servir à expliquer comment et pourquoi se produisent les procédés de la traduction examinés en traductologie sur corpus, à savoir l'explicitation et la normalisation.
\end{abstract}

\begin{abstract}
Concepts of domain conceptualisation and scene construal, adopted from cognitive linguistics, are outlined briefly and subsequently discussed in the context of translation, with the aim of explaining processing which may take place during translation. Of particular interest here is the link between domain conceptualisation in students and the development of their linguistic and translational competence. Data from think-aloud studies involving intermediate and more advanced students provide some evidence of the extent of these students' conceptual awareness while translating a text from German into English. The paper concludes by positing that models of cognitive processing underlying cognitive linguistics may also help to explain how and why processes of translation investigated in corpus-based translation studies, e.g. explicitation and normalisation, may come about.
\end{abstract}

\section{MOTS-CLÉS/KEYWORDS}

cognitive linguistics, domain conceptualisation, scene construal, cognitive concepts applied to translation, think-aloud studies

\section{Introduction}

The current research, part of which forms the basis for this paper, may be seen as an attempt to enhance the explanatory and predictive aspects of translation process research. Taking Toury's laws of translation behaviour (1995: 259-277) as a starting point, research was carried out with the aim of formulating a number of hypotheses about translation behaviour based on concepts from information processing and cognitive linguistic models and testing these hypotheses on sample translation process and product data. The hypotheses related to trends and likelihoods of occurrence during the translation process of a range of phenomena, with emphasis on the increase or decrease in likelihoods in conjunction with increasing linguistic and 
translational competence. This paper discusses domain conceptualisation and scene construal in translation, first defining these notions in a mainly cognitive linguistic framework, then presenting implications for translation processes, drawing on translation process data ${ }^{1}$ to illustrate the notions discussed.

\section{Models of Cognitive Processing}

\subsection{Linguistic Forms and Conceptual Structures}

Cognitive grammar was developed by Langacker in the eighties and it exemplifies the cognitive linguistic approach to language use. It argues for a unified perspective, where syntax and semantics cannot be considered as separate entities or components of language, where formalism is not an explicit aim of linguistic theory, and where meaning is determined by conceptualisation (Langacker 1987: 1-7). Linguistic forms thus reflect users' construal and conceptualisations of the world around them. The description of meaning with reference to cognitive processing assumes that it is possible, in theory, "to describe in a principled, coherent, and explicit manner the internal structure of such phenomena as thoughts, concepts, perceptions, images and mental experience in general" (Langacker 1987: 97-98).

Cognitive grammar relies on a view of language as symbolic. A symbolic unit consists of a phonological pole and a semantic pole and the relationship between them. The phonological pole is the linguistic representation. This is linked to a conceptual structure which functions as the semantic pole of the unit; a semantic structure is thus a "conceptualization tailored to the specifications of linguistic convention" (Langacker 1987: 99). While it is by no means novel to consider lexical items as being symbolic, it is not usual to think of grammar in the same way. Furthermore, cognitive linguistics considers linguistic structures to be motivated, rather than arbitrary, and believes they can be explained in terms of function (Radden 1992: 513). This cognitive linguistic view of language as symbolic corresponds, to some extent, to the structures proposed by Shreve and Diamond (1997) and the models of bilingual memory discussed by de Groot (1997). Shreve and Diamond posit that L1 forms and conceptual representations are stored separately and in a different location to L2 forms and conceptual representations, but that there may be stores of automatic connections linking L1 and L2 linguistic forms. This may be particularly true for the translator's knowledge storage since s/he activates L1-L2 connections often-perhaps more frequently than bilinguals, for example (Shreve and Diamond 1997: 247248). Moreover, the size of the linguistic forms involved in this direct connection situation may increase as translators become more experienced. De Groot presents a number of two-layer models of bilingual memory (de Groot 1997: 34-43; cf. Fig. 1). She discusses the fact that, in word translation, more concrete words will be translated faster and therefore may belong to the scenario labelled (c) below, with the two routes between L1 and L2 providing a fast connection. More abstract words appear to be better represented by (e) or (f). (d) is similar to (c) but takes account of weaker connections in L1 $\rightarrow$ L2 translation. Similarly, frequency of translation will strengthen connections, making them faster. 
FIGURE 1

Representations (a)-(f) of bilingual lexical and conceptual memory (de Groot 1997: 35-36)

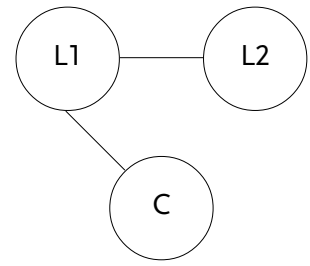

Bilingual lexical and conceptual memory

(a)

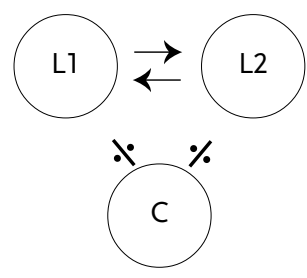

Bilingual lexical and conceptual memory

(d)

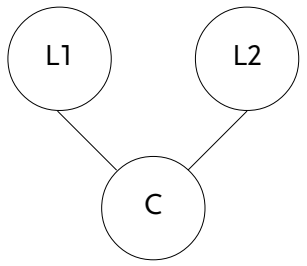

Bilingual lexical and conceptual memory

(b)

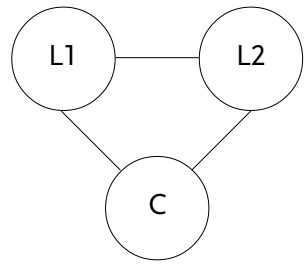

Bilingual lexical and conceptual memory

(c)

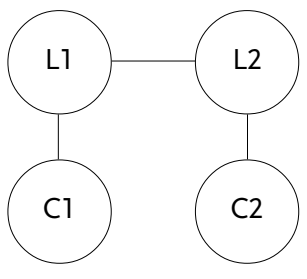

Bilingual lexical and conceptual memory

(e)

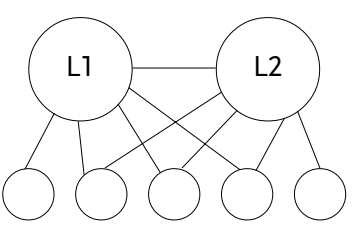

Bilingual lexical and conceptual memory

(f)

In these models of bilingual memory, only models (e) and (f) represent L1-L2 mappings where the L1 concept $(\mathrm{C} 1)$ and L2 concept $(\mathrm{C} 2)$ are considered separately. In (e), a single conceptual representation is activated for each of the two linguistic forms. In (f), the semantic representation is distributed over a number of units in memory, some of which may be shared by the L1 and L2 linguistic forms (de Groot 1997: 37). This is known as distributed conceptual representation. In a similar way, the cognitive grammar view is that the conventional knowledge of a construction that a speaker has is not given by a single structure, but is, instead, viewed as a full schematic network. In this way, when a speaker acquires and masters expressions which adhere to a specific pattern, they acquire cognitive routines which are an essential part of the speaker's grasp of linguistic convention (Langacker 1987: 411). Langacker also asserts that speakers learn the patterns they are exposed to and use these in preference to unfamiliar ones. A cognitive routine can become entrenched with recurrence, so that it forms a unit, and the concept is activated automatically by the linguistic structure.

From the discussion above, we can see that there are various possible scenarios in relation to L1-L2 mapping, and various roles played by concepts in this. The first is the notion of direct $\mathrm{L} 2 \rightarrow \mathrm{L} 1$ connections which bypass a conceptual representation, i.e. a store of ready-made $\mathrm{L} 2 \rightarrow \mathrm{L} 1$ equivalences, built up through experience and 
varying in chunk size, also depending on experience. Activation of this connection is fast, and the results, but not the intermediate steps of the process, may appear in STM (which means they may be available for verbalisation in a think-aloud situation). L1 and L2 elements which figure here may be presumed to be those used frequently, i.e. most salient mappings. The notion of cognitive entrenchment discussed by Langacker (1987: 100) is consistent with this understanding of retrieval from memory; a frequently-activated cognitive routine becomes conventionalised and develops unit status, which means it is activated as a cognitive whole, and the routine, once initiated, is carried out automatically.

The second issue relating to storage of linguistic and conceptual representations is the role played by different representations of concepts in L1 and L2. While beginner learners of a second language may match a newly acquired L2 linguistic structure to a previously existing L1 conceptual structure, as learners adopt conceptual structures and organisations of the L2, they are increasingly likely to associate an L2 linguistic structure with an L2 conceptual structure, where this is different from the L1 conceptual structure. In discussing the learning of a foreign language, Taylor, a cognitive linguist, believes formal differences between languages to be symptomatic of differences in conceptualisation. Difficulties may ensue in the learning of linguistic structures where they represent conceptual structures or categories which do not correspond fully with those of the L1 (Taylor 1989: 212-213). Our capability of conceptualising a domain in different ways (as happens in the use of metaphor for example), enables us to construct different conceptual systems as may be required in the learning of a second language and in translation between languages, given similar basic experience and similar conceptualisation of domains. A cognitive linguistic perspective would therefore appear to concur with the last model (f) of bilingual memory, since it sees conceptual structure as influencing language on the one hand, and as itself being influenced by (individual) experience on the other.

\subsection{Domain Conceptualisation and Scene Construal}

In cognitive grammar, the context by means of which a semantic unit is characterised is a domain, equivalent to frames ${ }^{2}$, scenes, schemas, or the idealised cognitive models_-ICMs ${ }^{3}$ - proposed by Lakoff (1987). For example, our notion of hypotenuse presupposes the conception of right-angled triangle (Langacker 1988: 53). Thus, right-angled triangle serves as the domain for the concept of hypotenuse. Domains are cognitive entities which possess properties of reducibility, dimensionality and can be locational or configurational (Langacker 1987: 147-154). Using a figure/ground distinction, the domain functions as the ground for a figure, which is the concept in question. Elsewhere, ground is defined as: "the speech act, its participants, and its immediate circumstances (such as the time and place of speaking)" (Langacker 1990: 9). Rather than being limited to one domain, most concepts, in fact, need to be characterised by specifications in more than one domain. Thus, the meaning of a lexical item is not split into semantic and pragmatic specifications, but rather is seen as encyclopaedic (Langacker 1987: 154). However, not all of the encyclopaedic specifications of a concept have equal status - some are more central than others. The more conventional, generic, intrinsic and characteristic a specification of a concept is, the more central to its meaning it is (Langacker 1987: 159-161). 
It is asserted in cognitive grammar that speakers can construe a given situation in a variety of different ways, and that these different construals are reflected in linguistic expression. Our ability to construe a situation in different ways is termed imagery by Langacker. The images can vary according to (a) the aspect selected (within selection there can be variations in domain, scale and scope) ${ }^{4}$, (b) the perspective from which the situation or scene is viewed (in relation to prominence and vantage point $)^{5}$, and (c) the level of abstraction or specificity at which it is perceived ${ }^{6}$. These variations in imagery are termed focal adjustments.

\subsection{Implications for Translation}

It can be hypothesised that some direct $\mathrm{L} 2 \rightarrow \mathrm{L} 1$ mapping may occur in translation in the form of cognitively entrenched routines, i.e. some L2 $\rightarrow$ L1 mapping may occur automatically and directly through connections between linguistic forms in the case of frequently translated forms, most likely to refer to concrete rather than abstract concepts. The more experienced the translator, the more of these direct mappings $\mathrm{s} /$ he may have at her/his disposal. Given their automatic nature, no intermediate steps would enter STM and there would be no conscious processing of conceptual information. Where $\mathrm{L} 2 \rightarrow \mathrm{L} 1$ translation of linguistic constructions does not constitute an entrenched routine, conceptual structures could be evoked, for which domains may provide context. It is conceivable, therefore, that a number of difficulties may arise in translation due to the nature of concepts, domains and domain specifications, and the relative ease or difficulty of mapping them from one language to another. Domain-oriented conceptualisation may be seen to be conducive to conceptual mapping between languages, where conceptual equivalence is a consideration in the translation task. It could therefore be expected that translation process data and translation products may provide evidence of the correlation between quality of translation product and (a) conceptual awareness and (b) domain awareness. Kussmaul has observed that the visualisation of scenes by students when translating has a positive influence on the quality of the translation product (Kussmaul 1997: 241247). Snell-Hornby (1988) has also commented on the use of a scenes-and-frames approach to translation. Thus, where there are differences in conceptualisation across languages, an awareness of these differences is likely to influence the translation process and to be reflected in the linguistic forms used in the target text. Domain conceptualisation, in turn, is likely to be influenced by degree of exposure to L2 concepts and conceptual organisations.

Pym, in defining translation competence, sees it as being the union of two skills, where the first is the ability to generate a target-text series of more than one viable term for a source text and the second is the ability to select quickly and confidently only one target text for a specified purpose and reader (Pym 1992: 281). While the generation of translation variants may be seen to relate to the activation and reinterpretation of salient meanings for a given phonological form, it can be postulated that the subsequent processing of these variants in such a way so that one is selected for use while the others are rejected may be regarded as a function of construal of conceptual content. As discussed above, the concept of imagery-defined as the construal of scenes in different ways encompassing differences in selection of substructures, in perspective, and in level of specificity or abstraction-may assist in the 
explanation of translation problems at the stages of both comprehension and production. From the point of view of comprehension, the construal of the situation as reflected in the source language can pose problems if the construal is unfamiliar to the reader. This may be because of lack of similarity with the more familiar L1 construals or lack of exposure to L2 construals, or the use of an unexpected or rather unusual construal in the L2. With regard to the generation of a translation, it can be assumed that the choice of a specific translation equivalent, given the production of a number of valid variants, represents a choice, not merely between different linguistic representations but between different construals of conceptual content.

Thus, where a number of translation variants are proposed, during the translation process, to express the same conceptual content, the difference in construal of that conceptual content, reflected in the different linguistic constructions or expressions, may be a determining factor in the choice of translation equivalent. Translators have varying degrees of awareness of differences and similarities in conceptual construal, and they are therefore likely to vary in terms of their perceived need to attempt to reflect or to alter the source-language construal when producing the target text. A shift in perspective from source language reader to target language reader may be reflected in choice of linguistic forms. Similarly, different linguistic forms may mirror differences in the degree of prominence given to aspects of a scene. Translators may also feel it necessary to choose linguistic structures which preserve or alter the figure/ground relationships of a scene. Alternatively, target language choices may be influenced by a need to maintain or change the degree of specificity embodied in linguistic choices. Greater experience of source language and culture is likely to lead to better recognition of the need to preserve or alter scene construal in terms of these features, and to the ability to do so more successfully.

A connection may be made between some of the differences in scene construal as described in the cognitive linguistic framework and the translation processes investigated in corpus-based translation studies. It has been postulated that there are features which may be common to the language of translation and which can be identified by comparing the language of translation with original language (both in considerable quantities and in machine-readable form). Features of translation for which some evidence has been found are simplification, explicitation and normalisation (Baker 1996). It can be seen from the examples given below that differences in selection, perspective or specificity of construal often involve one or more of these processes.

\section{Evidence in Translation Process and Product Data}

\subsection{Introduction}

Analysis of four think-aloud protocols from students (two moderately advanced and two less advanced, referred to as advanced and intermediate respectively) and their translation products serves to provide examples of the notions of processing outlined above. The text which they translated is an information leaflet produced by the Deutsches Museum in Munich and their task was to translate it from German into English for international visitors to the museum. The scope of this paper does not allow for discussion of the experimental conditions and methodological consider- 
ations, which received careful attention. I will focus instead on a number of specific choices which relate to conceptual structures and their reflection in linguistic structures. Where appropriate, verbalisations are quoted from the think-aloud protocols ${ }^{7}$.

\subsection{Direct Mapping}

All of the think-aloud protocols exhibit some direct L2 $\rightarrow \mathrm{L} 1$ mapping of lexemes, i.e. very rapid activation of $\mathrm{L} 1$ lexical forms after reading, recognising and comprehending L2 forms. There are some instances where direct mapping may be taking place but where some justification is made for the mapping. This appears to occur in instances where cognate forms are involved. In the production of the English information (singular) for the German Informationen (plural), for example, only one of the student translators externalises the transposing strategy from plural form to singular: "information / not informations information". Similarly, a direct link was made between German Motor and English engine by all students but one follows her suggestion by the comment that: "it can't be really motor it's engine".

\subsection{Domain Conceptualisation}

There is evidence of domain conceptualisation in the data produced, particularly but not exclusively, in the case of the advanced students. One of these students demonstrates throughout her translation task the use of extralinguistic or pragmatic knowledge to verify the semantic adequacy of the text relative to the reference world. She has previously visited the museum which is the subject of the text to be translated. As a result, she is reminded of certain aspects of her personal experience at various intervals in the translation process. For example, in relation to the various exhibits to be seen there, she remarks: "i don't remember seeing any of these". Her experience of the entrance hall: "where it's so full you can't see what you're doing" is mentioned, and, when processing information about ticket prices, she recalls: "i'm sure we paid three". When writing about the size and contents of the museum guide, she appears to draw on previous experience of museums in exclaiming: "a hundred and fortyfour sides bloody hell 1.340 lots of places to sit down then".

In contrast, lack of appropriate extra-textual conceptual awareness can be seen in the translation products of the intermediate students of a text segment which presents the Park+Ride system as a means of getting to the museum. They have some difficulty producing an accurate translation, either referring to the stations on the outskirts being served by the park-and-ride system, when in fact it is the city centre or the museum which benefits from the system, or describing the underground trains and trams as going to the outskirts, rather than originating there where car drivers switch from car to public transport. In both cases, a lack of experience of this system which is very prevalent in Germany (and increasingly in the UK) seems to emerge from their otherwise adequate translations of this sentence. The advanced students have no difficulty in conceptualising the reality reflected in the text, and one remarks "it'll be on the outskirts cos then that's why it's park and ride".

One of the intermediate students demonstrates a failed attempt to conceptualise the domain in order to deal with the lexical item Sondersammlung (referring to the museum's special collection). He believes this unit to be a reference to the admission 
prices for collectors: "hm sondersammlung 1.874 something / researchers collectors 2.447 really not sure". His dictionary does not help and he admits, after two long pauses, of over half a minute each: “i don't know". His attempt to make sense of this is: "maybe if you've got a collector's badge". The other students translate it adequately and without variants. This again highlights an inability to conceptualise the situation described on the part of that student (and a lack of reflection on the syntactic form of the noun in question).

Other examples of domain conceptualisation are from the advanced students. For example for the translation of Gestaltung (in the context of Höchstleistungen der Forschung, Erfindung und Gestaltung darstellen), a student resorts to the dictionary. Of the equivalents offered there, she explicitly decides to use development for two reasons: "i might go for development cos it just sounds a bit better and it's the bit which isn't 1.655 which isn't included there". Her decision appears to be based on a construal of the concepts embodied in the English pair research and development. The choice of translation equivalent on the part of the other advanced student is also influenced by the scientific context. From the four variants given by the dictionary, she chooses one, creation, on the basis that: "that's probably more to do with science".

In relation to the translation of Ausstellungsführer, one of the advanced students, when reading through the text at the outset, comments: "well that's probably got a name in english 1.228 which i can't check now / look it up if you could". Later, when translating, she reiterates this point of view: "the / museum guide i suppose it's called 1.088 but that will have an official title that's already been translated i suspect". The other advanced student first thinks: "i'd better put ausstellungsführer because it might actually be in 2.471 german / the word might be in german". However, she then reaches a similar conclusion to that of her fellow student: "it probably would be in english i'm doing this in english / the exhibition guide / surely". This is evidence for their conceptualisation of the scene in question and the elements it may incorporate.

Similarly, when translating Abbildungen, one of the advanced students makes an association with textbooks, but then rejects the term used in English textbooks: "oh what do you say in textbooks / em see figure 1.470 no". She then suggests pictures, but consults the dictionary: "see if it's got anything 1.470 useful in the dictionary", finding and using illustrations. Domain conceptualisation can also be observed where the other advanced student opts for current periodicals to translate laufende Zeitschriften: "this probably means periodicals rather than magazines wouldn't it because / they'd be /scientific journals". Having produced this justification, she contemplates and rejects the use of journals: "might say journals / good point / em / no periodicals is what you say". In relation to Urkunden, having found the suggestion of title deed, among others, in the dictionary, the same student asks: "why would autographs and title deeds be together" and instead of title deeds, decides to use documents "cos why would it be why would there be deeds / in a scientific museum". In the revision phase, she is again prompted to consider this: "that documents thing doesn't make sense / maybe it is deeds i don't know". A decision is taken: "i'll just leave it as documents".

The inclusion of a telephone number in the text prompts an advanced student to ponder its usefulness: "i suppose you could phone and make a booking to go and see these things". This reflects conceptualisation of the target reader and domain, as well as of the concepts behind the linguistic forms. A similar ability to conceptualise is seen in her treatment of information about opening times; the final date and time of 
closure meet with a reaction of bafflement and hilarity: "on the second wednesday in december / (laughs) from two p m / on the (laughs) second wednesday in december 3.298 why why why (...) 1.090 wednesday in december 3.476 is that is that some feiertag or something / it's mad". Later, when revising, the reaction is similar: "two p $\mathrm{m}$ on the second wednesday in december makes me laugh (laughs)". Although the other advanced student's product is almost identical, she verbalises considerably more in the process. She remarks in relation to Faschingsdienstag: "don't have fasching in england do we 2.474 now how do we translate / there must be 1.874 a word for it 1.637 wonder if there is" and "the date for it would be good enough". As discussed in relation to the recognition of source-text word forms, Karfreitag is completely unknown: "what's karfreitag for god's sake 4.161 a day when you can't use your car". She then reflects: "the first of may / that's mayday isn't oh no it's not / is the first of may always mayday". Although the immediate answer to this is: " $i$ think it is", she opts to write $1^{\text {st }}$ May. Pfingstsonntag and Fronleichnam are both unfamiliar: "pfingstsonntag what's that / is that palm sunday 1.549 i don't know" and "fronleichnam what on earth is that". The dictionary helps in all these instances. The final part of the sentence triggers a similar reaction to that elicited by her colleague mentioned above, in the form of laughter and: "why 3.224 that's bizarre".

The concept of Zehnerkarte is clearly conceptualised by the advanced student mentioned above for her references to a previous visit to the museum. She suggests book of ten tickets and adds "if you want to go there every sunday for two and a half months". Her fellow student also attempts to reflect on the reality expressed by the linguistic form, but with limited success, suggesting a ticket for ten, although she is unsure: "zehnerkarte 1.024 a ticket for ten is it / must be 1.274 no / can't be just a ticket for ten / can't cost seventy marks for ten people / what does that mean". The dictionary and a quick calculation change her mind but do not convince her of its usefulness: "maybe it can 3.087 seven marks each suppose it could do couldn't it 3.137 it must be 3.899 oh my goodness / right 4.111 why just have a ticket for ten that's so stupid".

In encountering the culture-specific concepts of $S$-Bahn and U-Bahn, the same advanced student wonders "how to explain these", and inserts an explanation for $S$ $B a h n$ and a cultural equivalent (underground) for U-Bahn. In relation to the abbreviation $M V V$, the other advanced student asks: "do i really need to know what $\mathrm{m} \mathrm{v} \mathrm{v}$ is". She attempts to give a long form for it: "munich verkehrsverband or münchner verkehrsverband" and offers a gloss in brackets munich public transport. As was the case earlier in the text where a telephone number was given, she questions the usefulness of the telephone number for non-speakers of German: "and they won't be able to understand a word you're saying (laughs) 2.068 okay you can try". The other students either omit the abbreviation or it leave as it is, although the other advanced student looks in the dictionary: "just check it's not 1.724 some important abbreviation 1.324 that i don't know anything about", and assumes, correctly, "it's probably something to do with verkehr isn't it munich / münchen verkehrs something or other". Given that it is not in the dictionary, she decides: "just leave it then 1.487 must be something (laughs)".

The intermediate students appear to have difficulty measuring and dispensing the amount of extratextual and conceptual information to draw on or build into their translation. In some cases, there is the tendency to over-compensate for differ- 
ences in concepts between the two languages, but in other cases, they lack the realisation that some conceptual considerations might be required. The conversion of prices in marks into sterling, for example, demonstrates misinterpretation on the part of the student concerned of the need for this kind of information. The use of Carnival Tuesday for Faschingsdienstag is also illustrative of overzealous identification with the source-text concepts to the detriment of accuracy in the target text. At the other extreme, the lacunae in the target text produced by both intermediate students do not help the target-text reader, and neither student appears to consider possible ways of eliminating these, even if this were to constitute mere speculation regarding an ideal or more realistic translation situation.

\subsection{Conceptualisation of Text Function and Form}

In the translation of the name of the museum and its address, the advanced students comment on a number of occasions and in doing so show clear awareness of the meaning and function of this part of the text (in essence a logo/letterhead), and it is this concept rather than the linguistic forms which they translate. In contrast to the conceptual awareness described above, there is quite often a lack of conceptual awareness of this kind among the intermediate students. This can be seen in an attempted translation of the museum's name and address, thus not considering the significance and role of the lexical items in the text and context. Similarly, they omit telephone and fax numbers.

\subsection{Linguistic Conventionality}

Linguistic conventionality is seen to be a deciding factor in the translation of Naturwissenschaften, for which suggestions of science, the sciences, natural science, and natural sciences are produced. One of the advanced students attempts to unravel this: "naturwissenschaften is just like sciences", and later: " $i$ never really understood the difference between naturwissenschaften and sort of biology and things like that" and: "i suppose it's plural if it's sciences and singular if it's biology or something". In spite of this conceptual difficulty perceived here, the ultimate decision for usage in the case of both advanced students is determined by the conventionality of the pairing science and technology in English, which both regard as being linguistically conventional: we hear "the history of science and technology that's the way we'd put it isn't it" from one and "usually say science and technology sort of as a 2.366 a set phrase" from the other. The two intermediate students are not consistent in their translation equivalents for this term.

\section{Focal Adjustments in Scene Construal}

\subsection{Target Reader Perspective}

It can be anticipated that, in cases where translators consider target readership, they may attempt to construe scenes from the perspective of the target reader, and linguistic choices may be influenced by this. Explicit expression of this strategy can be found in the think-aloud protocols. One of the advanced students voices concern on 
a number of occasions during this task that English readers should be considered and her choice of linguistic forms reflects her English-reader-centred approach to construal. For example, she first comments that "deutsches museum / museum you would keep the same cos it's a name", and then immediately questions this decision: "what do english readers say 1.067 would you call it german museum", adopting the viewpoint of the target reader. She tries again to justify her initial decision: "well it's in germany so it's probably called / deutsches museum", using a figure/ground distinction. For the address, she states: "that's a / an address / keep that the same", but she then realises that a change from München to Munich will be necessary: "actually we'd put munich wouldn't we / not münchen / cos 3.797 it's for english people i think". A deliberate change of perspective in scene construal due to her concern for "English readers" causes her to add an international dialing code and country code as prefixes for the telephone, fax and information line numbers, thus once again seeking to provide a ground which the target readership, in her opinion, requires (although it is in fact superfluous in this case). Elsewhere, the same student comments: "opening times is what you say in english isn't it yes". She has some difficulty with the use of the 24-hour clock: "from nine till fi / oops / from / nine / to would you say seventeen you would / in england / well you'd have to because you'd be in germany / from nine to seventeen 2.412 o' clock". In the revision phase she changes her mind: " $i$ think i'll put nine to five not nine to seventeen / cos in england we just don't say that do we" and "in fact you don't even need to put clock do i why would i put clock from nine to five / you don't need to put clock that's stupid", thus opting for the 12-hour system.

With regard to the translation of laufende Zeitschriften, we also see evidence of the other advanced student adopting a target text reader oriented perspective. She suggests current editions, then periodicals, then editions of periodicals and current periodicals. She worries: "will they understand that it's periodicals and not volumes" and, in order to make this clear, reverts to current editions.

\subsection{Selection of Aspects for Prominence}

For the document title, Informationen für Ihren Besuch, one of the advanced students first proposes information for your visit, then changes this to information about the museum. She immediately reverts to her initial suggestion, and comments on the use of your in her translation, considering this to be both "quite personal" and quite appropriate. While information about the museum would certainly have been functionally adequate, it would have reflected a different scene construal, namely one in which the museum, rather than the visit is given prominence, and this is clearly acknowledged by this student in deeming her suggestion to be "quite personal". One of the intermediate students chooses to give even greater prominence to the visitor rather than to his/her visit by using Visitor's information, while the other considers stay and trip as equivalents for Besuch, following initial activation of the more salient visit. This reveals that the cognitive model or domain of Besuch is connected to concepts of holidays, trips and stays. However with Museum as a ground for the concept of Besuch, trip (focus on journey) and stay (focus on duration of visit, usually at least overnight) is rejected in favour of visit (location-oriented with focus on events while there). 
In relation to the concept referred to in German as Automatische Telefonauskunft, all four students appear to have a conceptualisation of this service, but interestingly their choices of translation equivalents profile different aspects of the concept, i.e. the service, the information and its recorded/automatic nature (pre-recorded telephone information line; recorded information; automatic telephone information service), although all seem to reflect a realistic and conventional conceptualisation. The published English translation of this text uses, by contrast, answering machine, which, in English, profiles, inaccurately, the system's ability to answer a call, i.e. by taking a message, rather than its ability to impart information to you, i.e. through a rather lengthy but informative pre-recorded message, which is the case. Here and elsewhere, one of the advanced students feels it useful to alert readers to the fact that this service will be in German by adding German in brackets. This addition to the translation is clearly a case of a greater degree of specificity of linguistic form, in a need, perceived by this student, for additional information for the target text reader, thus rendering the concept more explicit.

In translating das erste Automobil, we can see that the concept is construed differently by the students. Both advanced students wonder whether to call it a car or an automobile. One comments: "automobile should we don't people talk about the car 1.219 no automobile same 1.572 the first may be something other than the car i don't really know", while the other also reflects on this: "would you put automobile cos that's what they were called in those days or would you put car 1.709 no i think you'd put the first automobile wouldn't you cos 2.293 that's what it would have been called the first 1.247 automobile". Both of these deliberations reflect a construal which considers the temporal dimension and its potential reflection in linguistic forms.

Different construals of quantity are also evident in the translation products. The number of models, experiments and demonstrations is expressed in German as viele Hunderte and translated literally as many hundreds at first by two students who subsequently drop the many, one commenting: "you would just leave out many". The published translation, presumably with access to more detailed information, can give a more specific rendering of over one thousand.

\subsection{Lexical Choices and Scene Construal}

The literal rendering of one of the verbs in the text constitutes a source of weakness in the translation products, recognised as a problem by only one of the advanced students, but not solved. The item in question is the verb versuchen in German, rendered by all of the students as try or attempt. As stated by that advanced student, the use of try or attempt in relation to the aims of the museum does not convey the notion that these aims are met: " $i$ don't really like that / it tries to show / i mean it should be doing it well".

The lexical item systematisch is also seen to be problematic. One of the advanced students produces systematic but is not satisfied with it: "we'll put it down but 1.535 underline it and come back to it". In the revision phase she decides to look in the dictionary for an alternative but is not very hopeful of finding one: "see if there is another reasonable i can't imagine there is systematic if not i'll just leave it out cos it looks so crap". This is indeed what happens. Another student also omits it but two use systematic, both during the translation process and in the product, one commenting, 
however, that: "systematic exhibition's bizarre". The problem appears to be one of construal. The source text uses systematisch as an attribute of Ausstellung, whereas in English systematic is more likely to apply to some other feature of the exhibition, e.g. ordering or arrangement.

\subsection{Grammatical Choices and Scene Construal}

The prepositional phrase in initial position (Vor dem allgemeinen kulturgeschichtlichen Hintergrund) results in the use of four prepositional phrases in English, each of which has a different preposition or prepositional phrase, and each of which occurs at a different position within the English sentence. One of the advanced students is somewhat baffled by the use of vor and consults her dictionary in an effort to solve the problem but concludes "don't really know about that one". She tries for, in the name of and because of, eventually reverting to for but indicating dissatisfaction: "i'll see about that come back to that later see how it fits in". The other advanced student uses from without offering alternatives or deliberating it at all. The two intermediate students use in the context of and ahead of respectively, without consideration of alternatives. While all students adhered to the notion of background (Hintergrund), none uses the preposition against to denote the spatial relationship between the background and the concept which it grounds. It seems therefore that the scene was not visualised adequately, given the prepositions produced in English, and that the need for a different construal of that spatial relation in English remained unrecognised and was thus problematic in terms of production of an adequate translation. Elsewhere, another prepositional phrase in initial position is dealt with in a different manner by each student (Neben historischen Originalen). One of the advanced students immediately produces together with. The other students try out next to and beside before choosing alongside in two cases, and along with in another. This latter translation may indicate a concern with the salient locational aspect of the relation expressed with neben, which is also reflected in their other suggestions such as next to, whereas the student who chose together with may be perceived as viewing the scene with less emphasis on proximity and more on space sharing.

While the two advanced students mirror the German structure (eine Spezialbibliothek für die Geschichte...) by using a preposition, one of the intermediate students makes the relationship between the two nouns more explicit by writing dealing with, his justification being: "i'll put dealing with / more sophisticated". While this does not have implications of inaccuracy, misconstruals are evident on a number of occasions resulting in the intermediate students producing factually inaccurate translations. Two examples illustrate this. By translating a section with there is a reference library, the student incorrectly implies that this is a different library than the one introduced in the previous sentence. Secondly, what should have been from $2 p m$ on the second Wednesday in December was rendered as at 2pm from the second Wednesday in December and from 2pm every second Wednesday.

\section{Conclusions}

Direct mappings are seen to occur, especially for concrete concepts and in the case of the more advanced students. Awareness of conceptual differences across the two lan- 
guages is evident particularly in the processing of the two more advanced students who make reference to linguistic conventions of English and the conceptual structures reflected by English constructions. It is obvious that both (and one in particular) appear on a number of occasions to visualise the scene or domain in question and to verbalise observations related to this visualisation or expectations resulting from it. It is also clear from the process data that they conceptualise the function, use and readership of the target text. The two intermediate students, in contrast, do not appear to do this at all, or do so incorrectly and their translation product suffers as a result. Thus a lack of conceptual awareness is clearly evident in both translation process and product.

Shifts in perspective from source-text reader to target-text reader occur especially in the translating of the more advanced students, although this is not always successfully executed. They appear to be more aware of different source-language and target-language scene construals and this awareness is reflected in a number of verbalisations in their think-aloud protocols. They too have problems with this at times, especially in coping with differences in prepositional usage to designate locational or spatial relations. They can both be seen to opt for more specific renderings in a desire-often articulated-to help the target reader.

Analysis of the data from this very small case study shows that it is possible to trace some cognitive processing in translation in empirical data and it is clear that there are useful concepts and models used elsewhere (e.g. in models of information processing and in cognitive linguistics) which can help to explain some processes which occur in translation. Thus, an important implication of this brief discussion and analysis is that theoretical models of cognitive and language processing may be used to provide hypotheses for investigation of translation process and product data. Furthermore, it may also be useful to combine this kind of process-based analysis with corpus-based translation analysis, since verbalisations can clearly provide some evidence of deliberate, conscious strategies ${ }^{8}$, of a global or local nature which may, in turn, be explained using models of cognitive processing. Conscious explicitation and normalisation processes, for example, are verbalised in a number of the examples discussed above, and the notion of cognitive entrenchment is consistent with the idea that translators conventionalise or normalise, while focal adjustment of scene construal is often reflected in explicitation of linguistic expression.

\section{NOTES}

1. In spite of acknowledged difficulties with the think-aloud method, the empirical investigations referred to here usefully serve the purpose of providing some examples of translation processes observable via verbalisations.

2. Frames, originally conceived by Fillmore as linguistic structures associated with a particular scene (Fillmore 1977), have evolved to be considered in a more cognitive sense as cognitive models representing the knowledge and beliefs pertaining to specific and frequently recurring situations (Ungerer and Schmid 1996: 211).

3. Lakoff asserts that a concept can only be defined relative to an ICM, that ICMs may or may not fit our understanding of the world and that they do not have to be consistent with one another. According to Lakoff, it is this comparison of ICM and world understanding which enables us to make definitions, establish categories and recognise prototypes (Lakoff 1987).

4. Langacker (1987: 117) gives examples to illustrate differences in domain selection for the lexical item close: 
The tree is quite close to the garage (spatial domain)

It's already close to Christmas (abstract temporal domain)

That paint is close to the blue we want for the dining room (colour domain)

Steve and his sister are very close to one another (emotive domain).

Similarly, there may be differences in scale:

The two galaxies are very close to one another

San José is close to Berkeley

The runner is staying close to first base

The sulphur and oxygen atoms are quite close to one another in this type of molecule.

Scope relates to the portions of a scene that are specifically included in a construal, for example body is the immediate scope for head, arm, leg, torso. Thus, whereas (i) below is conceptually acceptable, examples (ii)-(iv) depict increasingly inappropriate scope relations and thus decreasing acceptability (Langacker: 119):

(i) A body has two arms

(ii) A body has two elbows

(iii) An arm has five fingernails and fourteen knuckles

(iv) A body has 28 knuckles

5. The figure/ground distinction is used in the discussion of perspective of construal, whereby the figure is perceived as more prominent, standing out from the rest, which is the ground (Langacker 1987: 121). Thus, the way in which we construe a mentally constructed scene is described as though we were actually perceiving the scene. The second feature of perspective is viewpoint. This includes the vantage point (i.e. the point from which we view the scene) and the orientation (i.e. the alignment with respect to the axes of the visual field).

6. This third form of focal adjustment concerns the level of specificity of language expression. For example, tall is abstract or schematic relative to over 6 feet tall, which in turn is more abstract or schematic relative to about 6 feet 5 inches tall. Our ability to organise linguistic terms into schematic hierarchies demonstrates our ability to conceptualise at varying levels of schematicity (Langacker 1987: 132-133).

7. The transcription of the think-aloud sessions follows conventional practice in terms of indicating duration of unfilled pauses, e.g. 1.453 represents 1.453 seconds. In addition, ' $~ ’$ ' is used to indicate significant pauses of less than one second in duration.

8. It must be stressed that think-aloud protocols will only provide evidence of controlled processes. Subconscious or uncontrolled processes, e.g. explicitation processes of the kind discussed in Olohan and Baker 2000, cannot be observed in this way.

\section{REFERENCES}

BAKER, M. (1996): “Corpus-based translation studies: The challenges that lie ahead," Terminology, LSP and Translation: Studies in Language Engineering in Honour of Juan C. Sager (H. SomERS, ed.), Amsterdam and Philadelphia, John Benjamins, pp. 175-186.

De Groot, A. M. B. (1997): “The cognitive study of translation and interpretation: Three approaches," Cognitive Processes in Translation and Interpreting, London, Sage, pp. 25-56.

Fillmore, C. (1977): "Scenes-and-frames semantics," Linguistic Structures Processing (A. Zampolli, ed.), Amsterdam, North Holland Publishing Co., pp. 55-81.

GiorA, R. (1997): "Understanding figurative and literal language: The graded salience hypothesis," Cognitive Linguistics, 8-3, pp. 183-206.

Kussmaul, P. (1997): “Comprehension processes and translation. A think-aloud protocol (TAP) Study," Translation as Intercultural Communication (M. SNell-Hornby, Z. JetTMArová and K. KaindL, eds.), Amsterdam and Philadelphia, John Benjamins, pp. 240-259.

Lakoff, G. (1987): Women, Fire and Dangerous Things: What Categories Reveal about the Mind, Chicago, Chicago University Press.

Langacker, R. W. (1987): Foundations of Cognitive Grammar Vol. 1: Theoretical Prerequisites, Stanford, Stanford University Press.

- (1990): "Subjectification," Cognitive Linguistics, 1-1, pp. 5-38.

Olohan, M. and M. Baker (2000): "Reporting that in translated English: Evidence for subconscious processes of explicitation?," Across Languages and Cultures, 1-2. 
Рyм, A. (1992): “Translation error analysis and the interface with language teaching," Teaching Translation and Interpreting: Training Talent and Experience (C. Dollerup and A. LoddeGAARD, eds.), Amsterdam, John Benjamins, pp. 279-288.

Radden, G. (1992): “The cognitive approach to natural language," Thirty Years of Linguistic Evolution (M. PüTZ, ed.), Amsterdam and Philadelphia, John Benjamins, pp. 513-541.

Shreve, G. M. and B. J. Diamond (1997): "Cognitive processes in translation and interpreting: Critical issues," Cognitive Processes in Translation and Interpreting (J. DANKs et al., eds.), London, Sage, pp. 233-251.

Snell-Hornby, M. (1988): Translation Studies: An Integrated Approach, Amsterdam and Philadelphia, John Benjamins.

TAYlor, J. R. (1989): Linguistic Categorisation. Prototypes in Linguistic Theory, Oxford, Clarendon Press.

Toury, G. (1995): Descriptive Translation Studies—and Beyond, Amsterdam and Philadelphia, John Benjamins.

Ungerer, F. and H.-J. Schmid (1996): An Introduction to Cognitive Linguistics, London and New York, Longman. 